\title{
Amyloid $\beta$ directly interacts with NLRP3 to initiate inflammasome activation: identification of an intrinsic NLRP3 ligand in a cell-free system
}

Ayaka Nakanishi ${ }^{1,2+}$, Naoe Kaneko ${ }^{1 \dagger}$, Hiroyuki Takeda ${ }^{3}$, Tatsuya Sawasaki ${ }^{4}$, Shinnosuke Morikawa ${ }^{1}$, Wei Zhou ${ }^{1}$, Mie Kurata ${ }^{1}$, Toshihiro Yamamoto ${ }^{1}$, Sheikh Mohammad Fazle Akbar ${ }^{1}$, Tamotsu Zako $^{2}$ and Junya Masumoto ${ }^{1 *}$ (D)

\begin{abstract}
Background: Alzheimer's disease is a neurodegenerative disease characterized by the interstitial deposition of amyloid $\beta$ (AB) plaque, which is thought to be related to chronic neuroinflammation. $A \beta$ is known to make fibrils via oligomers from monomers. A $\beta$ has been reported to activate the NLRP3 inflammasome in infiltrated macrophages. NLRP3, an intracellular pattern recognition receptor, has been reported to recognize numerous pathogens and/or metabolites and form complexes with adopter protein ASC to make the inflammasome, an interleukin (IL)-1 $\beta$-processing platform. Although reactive oxygen species from mitochondria have been reported to be involved in the activation of the NLRP3 inflammasome in microglial cells upon the deposition of A $\beta$, whether $A \beta$ directly or indirectly activates the NLRP3 inflammasome remains unclear.

Methods: We prepared monomers, oligomers, and fibrils of $A \beta$, which promoted the interaction between NLRP3 and each form of A 3 and analyzed the interaction between NLRP3 and ASC induced by each form of $A \beta$ in a cell-free system with the amplified luminescent proximity homogeneous assay. We also confirmed the physiological relevance in a cell-based assay using human embryonic kidney 293T cells and human peripheral mononuclear cells.

Results: Monomers, oligomers, and fibrils of $A \beta$ were successfully prepared. $A \beta$ oligomers and fibrils interacted with NLRP3. A $\beta$ oligomers and fibrils induced the interaction between NLRP3 and ASC. However, A $\beta$ monomers did not interact with NLRP3 or induce interaction between NLRP3 and ASC in the cell-free system, and IL-1 $\beta$ was not secreted according to the cell-based assay.

Conclusion: Oligomerized A $\beta$ originating from non-toxic A $\beta$ monomers directly interacted with NLRP3, leading to the activation of the NLRP3 inflammasome. This may be an attractive target for the treatment of Alzheimer's disease.
\end{abstract}

Keywords: Alzheimer's disease, Amyloid $\beta$, NLRP3, Interleukin-1 $\beta$, Inflammasome, Cell-free

\footnotetext{
* Correspondence: masumoto@m.ehime-u.ac.jp

${ }^{\dagger}$ Ayaka Nakanishi and Naoe Kaneko contributed equally to this work.

1 Department of Pathology, Ehime University Graduate School of Medicine and Proteo-Science Centre, Shitsukawa 454, Toon, Ehime 791-0295, Japan Full list of author information is available at the end of the article
}

(c) The Author(s). 2018 Open Access This article is distributed under the terms of the Creative Commons Attribution 4.0 International License (http://creativecommons.org/licenses/by/4.0/), which permits unrestricted use, distribution, and reproduction in any medium, provided you give appropriate credit to the original author(s) and the source, provide a link to the Creative Commons license, and indicate if changes were made. The Creative Commons Public Domain Dedication waiver (http://creativecommons.org/publicdomain/zero/1.0/) applies to the data made available in this article, unless otherwise stated. 


\section{Background}

Alzheimer's disease (AD) is a neurodegenerative disease, characterized by neuronal cell death accompanied by the interstitial deposition of amyloid $\beta(\mathrm{A} \beta)$ plaque and cytoplasmic phosphorylated tau protein, and neurofibrillary tangles (NFTs) [1]. Recently, evidence was found that the innate immune system was closely related to neurodegenerative diseases such as AD [2].

The inflammasome has been identified as an intracellular complex that plays an important role in innate immune responses against pathogens and toxic metabolites. NACHT, LRR, and PYD domain-containing protein 3 (NLRP3), an intracellular pattern recognition receptor, has been reported as a component of the intracellular innate immune receptor complexes with adopter protein ASC that forms inflammasome, an interleukin (IL)-1 $\beta$-processing platform [2-4].

We previously developed the NLRP3 inflammasome in a cell-free system to detect intrinsic and extrinsic directly interacting ligands [5]. The NALP3 inflammasome was reported to be a sensor of phagocytosed $A \beta[6]$; however, $A \beta$ did not induce an interaction with NLRP3 or apoptosis-associated speck-like protein containing a caspase recruitment domain (ASC) in the cell-free system [5].

There have been several reports that $A \beta$ oligomerization, which is thought to play an important role in the innate immune response and cell death, is required for the pathogenesis of $\mathrm{AD}[7,8]$. It has been suggested that reactive oxygen species (ROS) are involved in the initiation of this innate response related to NLRP3 inflammasome activation, which may play a significant role in promoting the development of $\mathrm{AD}$ [9].

Currently, numerous ligands, including $\mathrm{A} \beta$, have been reported to activate the NLRP3 inflammasome; however, none were confirmed at the molecular level in previous reports. Thus, the purpose of our study was to clarify whether $A \beta$ oligomers directly or indirectly activate the NLRP3 inflammasome. In order to confirm direct interactions, we used the cell-free system in this study.

\section{Methods}

\section{Regents}

A 342 was purchased form the Peptide Institute (Ibaraki, Osaka, Japan). Anti-A $\beta$ mouse monoclonal antibody (6E10) and anti-mouse immunoglobulin $\mathrm{G}$ (IgG) were purchased from BioLegend (San Diego, CA, USA) and R\&D Systems (Minneapolis, MN, USA), respectively. Thioflavin T (ThT) was obtained from Sigma-Aldrich (St. Louis, MO, USA). Anti-FLAG monoclonal antibody M2 (F1804) was purchased from Sigma-Aldrich (St. Louis, MO, USA). Human IL-1 $\beta$ ELISA Set II was purchased from BD Biosciences (San Jose, CA, USA). Anti-cleaved caspase-1 rabbit monoclonal antibody (Asp297) (D57A2) (S4199) was purchased from Cell Signaling Technology (Danvers, MA, USA). MCC950 (PZ0280) was purchased from Sigma-Aldrich (St.
Louis, MO). Isoliquiritigenin (I0822) was purchased from Tokyo Chemical Industry Co., Ltd. (Tokyo, Japan).

\section{Preparation of $\mathrm{A} \beta$ monomers, oligomers, and fibrils} A 342 stock solution $(400 \mu \mathrm{M})$ was prepared by dissolving the lyophilized peptide in $0.1 \%$ ammonia solution. The oligomerization reaction was initiated by diluting the stock solution in 10-times diluted phosphate-buffered saline (PBS) (final concentration: $45 \mu \mathrm{M}$ A 342 monomers, $\mathrm{pH}$ 7.4) at room temperature. For oligomer and fibril formation, A $\beta 42$ monomers $(45 \mu \mathrm{M})$ were incubated at room temperature for $14 \mathrm{~h}$ (oligomers) or at $37^{\circ} \mathrm{C}$ for $48 \mathrm{~h}$ (fibrils).

\section{Native polyacrylamide gel electrophoresis and Western blotting analysis}

The A $\beta$ samples $(7.5 \mu \mathrm{L})$ were mixed with the native-PAGE sample buffer $(2.5 \mu \mathrm{L})$ and used for native-PAGE with an $8 \%$ gel. A NativeMark Unstained Protein Standard (Invitrogen) comprising 1236 IgM Hexamer (1236 kDa), Apoferritin band 1 (720 kDa), Apoferritin band $2(480 \mathrm{kDa})$, and bovine serum albumin $(66 \mathrm{kDa})$ was used as a molecular mass marker. Following transfer to a nitrocellulose membrane, the membrane was blocked with 5\% skim milk in Tris-buffered saline including $0.05 \%$ Tween20 (TBST) for $1 \mathrm{~h}$ at room temperature. Then, the membrane was incubated with anti-A $\beta$ (6E10, 1:5000) for $1 \mathrm{~h}$ at room temperature. After washing with TBST, it was incubated with the secondary antibody $(1: 10,000)$ for $1 \mathrm{~h}$ at room temperature. After washing with TBST, proteins were visualized using the ECL Plus Western Blotting Detection System (GE Healthcare, Chalfont St. Giles, UK). Luminescence was detected by the LAS4000 mini luminescent Image Analyzer (Fujifilm, Tokyo, Japan).

\section{Scanning electron microscopic analysis}

The $10 \mu \mathrm{M} A \beta$ samples were dropped onto a silicon wafer and allowed to air-dry. Samples were observed at an acceleration voltage of $15 \mathrm{kV}$ using a field-emission scanning electron microscope (FE-SEM, JSM7001FA, JEOL: Tokyo, Japan).

\section{Thioflavin T spectroscopic assay}

The A $\beta$ samples $(5 \mu \mathrm{M})$ were mixed with a ThT solution $(50 \mu \mathrm{M})$ in PBS. Then, ThT fluorescence was measured using a microplate reader (Safire2, TECAN, Mannedorf, Switzerland) at an excitation wavelength of $450 \mathrm{~nm}$ and emission wavelength of $490 \mathrm{~nm}$ [10].

\section{Recombinant protein synthesis}

pDONR221-NLRP3 and pDONR221-ASC were inserted into pEU-E01-GW-bls-STOP and pEU-E01-GW-STOP, respectively, for cell-free protein expression, as previously reported [5]. The entire cDNA of GFP was derived from pEU-E01-bls-GFP. The open reading frame of GFP without 
a stop codon was modified in a two-step polymerase chain reaction using the following primer sets:

forward primer S1-GFP_F: 5'-CCACCCACCACCAC CAATGGTGAGCAAGGGCGAGG-3' with reverse primer GFP-T1(F)_R: 5' - TCCAGCACTAGCTCCAGACTTGTA CAGCTCGTCCATGC -3 '. The second step was carried out using the following primer sets: attB1-S1: 5'-GGGG ACAAGTTTGTACAAAAAAGCAGGCTTCCACCCACC ACCACCAATG-3' and attB2-T1: 5'-GGGGACCAC TTTGTACAAGAAAGCTGGGTCTCCAGCACTAGCTC CAGA-3'. PCR products were inserted into a Gateway pDONR $^{\mathrm{m}} 221$ Vector (pDONR221) (Life Technologies, Carlsbad, CA, USA) using the Gateway ${ }^{\circ}$ BP Clonase ${ }^{\text {Th }}$ II Enzyme mix (Life Technologies, Carlsbad, CA, USA) to generate entry clones. The GFP entry clones pDONR221-GFP was inserted into pEU-E01-GW-bls-STOP using the Gateway $^{\text {tux }}$ LR Clonase ${ }^{\text {tn }}$ II Enzyme mix (Life Technologies, Carlsbad, CA, USA) for cell-free protein expression. The constructed plasmids were used to synthesize specific proteins with a WEPRO1240 Expression Kit (Cell-free, Inc., Matsuyama, Japan), followed by Western blotting to confirm prompt protein synthesis.

\section{Amplified luminescent proximity homogeneous assay}

Synthesized protein-protein interactions were assessed using the amplified luminescent proximity homogeneous assay (ALPHA). A total of $100 \mathrm{ng}$ of each protein was added to ALPHA buffer [100 mM Tris- $\mathrm{HCl}(\mathrm{pH} 8.0)$, $0.01 \%(v / v)$ Tween20], $1 \mathrm{mg} / \mathrm{mL}$ of BSA, $17 \mu \mathrm{g} / \mathrm{mL}$ of streptavidin-conjugated ALPHA donor beads (PerkinElmer, Waltham, MA, USA), $17 \mu \mathrm{g} / \mathrm{mL}$ of protein-A-conjugated ALPHA acceptor beads, and $5 \mu \mathrm{g} / \mathrm{mL}$ of anti-FLAG mAb M2 and incubated in a 1/2ALPHAPlate-96 shallow well (PerkinElmer, Waltham, MA, USA) at $25{ }^{\circ} \mathrm{C}$ for $24 \mathrm{~h}$. The fluorescence emission signals of each well were measured using an EnSpire ${ }^{\mathrm{mm}}$ Multimode Plate Reader (PerkinElmer, Waltham, MA, USA).

The interaction between NLRP3 and A $\beta$ was assessed by incubating $100 \mathrm{ng}$ of NLRP3-FL-Btn with $5 \mu \mathrm{g} / \mathrm{mL}$ of anti-A $\beta$ mAb (6E10) (BioLegend, San Diego, CA, USA), $17 \mu \mathrm{g} / \mathrm{mL}$ of protein-A-conjugated ALPHA acceptor beads, and $17 \mu \mathrm{g} / \mathrm{mL}$ of streptavidin-conjugated ALPHA donor beads for $24 \mathrm{~h}$ with the indicated concentrations of $\mathrm{A} \beta$ and incubated in a 1/2ALPHAPlate- 96 shallow well (PerkinElmer, Waltham, MA, USA) at $25{ }^{\circ} \mathrm{C}$ for $24 \mathrm{~h}$. The fluorescence emission signals of each well were measured using an EnSpire ${ }^{\mathrm{Tm}}$ Multimode Plate Reader (PerkinElmer, Waltham, MA, USA).

\section{Cell-based assay using human embryonic kidney (HEK) 293T cells}

Human embryonic kidney (HEK) 293T cells were maintained in DMEM (Gibco) with 10\% heat-inactivated FBS, penicillin, and streptomycin. Transfection was carried out with the calcium phosphate method. A total of $1 \times 10^{5}$ HEK 293T cells were co-transfected with the indicated amount of non-tagged expression plasmids such as pcDNA3-NLRP3, pcDNA3-ASC, pcDNA3-caspase-1, and pcDNA3-IL-1 $\beta$. After hours, the transfection medium was changed to fresh medium together with $A \beta$ monomers, oligomers, or fibrils at the indicated concentrations. IL-1 $\beta$ concentrations in the culture supernatants were measured $16 \mathrm{~h}$ after medium change using the enzyme-linked immunosorbent assay (ELISA) with specific human IL-1 $\beta$ antibodies (BD Biosciences, San Jose, CA, USA) according to the manufacturer's instructions.

\section{Cell-based assay using human peripheral blood mononuclear cells}

Human peripheral blood mononuclear cells (MNCs) were separated by Ficoll gradient centrifugation (GE Healthcare Bio-Sciences AB, Piscataway, NJ, USA) according to the manufacturer's instructions. The cells were cultured in 24-well flat-bottom plates (BD Biosciences, San Jose, CA, USA) at a final cell density of $5 \times 10^{5} / \mathrm{mL}$ in a volume of $1 \mathrm{~mL}$ of RPMI1640, including $10 \%$ FBS with $\mathrm{A} \beta$ oligomers, and lipopolysaccharide (LPS) or left untreated for $16 \mathrm{~h}$ at $37{ }^{\circ} \mathrm{C}$ in a humidified atmosphere with $5 \% \mathrm{CO}_{2}$. Concentrations of IL- $1 \beta$ in the culture supernatants were measured by ELISA with specific human IL- $1 \beta$ antibodies (BD Biosciences, San Jose, CA, USA) according to the manufacturer's instructions.

\section{Endotoxin quantification in $A \beta$}

The levels of endotoxin contamination in $A \beta$ monomers, oligomers, and fibrils were quantified by the Limulus amebocyte lysate assay using Endospecy, a chromogenic endotoxin-specific assay kit, according to the manufacturer's instructions (Seikagaku-Biobusiness, Tokyo, Japan).

\section{Statistical analysis}

Results are presented as the mean \pm standard deviation of triplicate data acquisition, and the significance of differences was evaluated using the Mann-Whitney $U$ test. A $p$ value $<0.05$ was considered significant.

\section{Results}

$A \beta 42$ oligomerizations and morphological changes

$A \beta$ oligomerization reactions successfully progressed, as confirmed by native PAGE followed by Western blotting analysis, the ThT assay, and SEM analysis (Fig. 1). As shown in Fig. 1a, the formation of soluble oligomers was confirmed. The ThT assay revealed that fibrils were not included in the oligomer sample (Fig. 1b). Fibril formation was supported by the ThT assay and SEM analysis (Fig. 1b, c). Native PAGE analysis demonstrated that oligomers and monomers were not included in the fibril sample (Fig. 1a). 
a

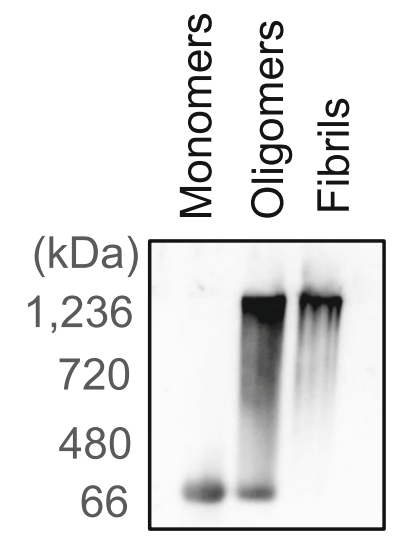

C

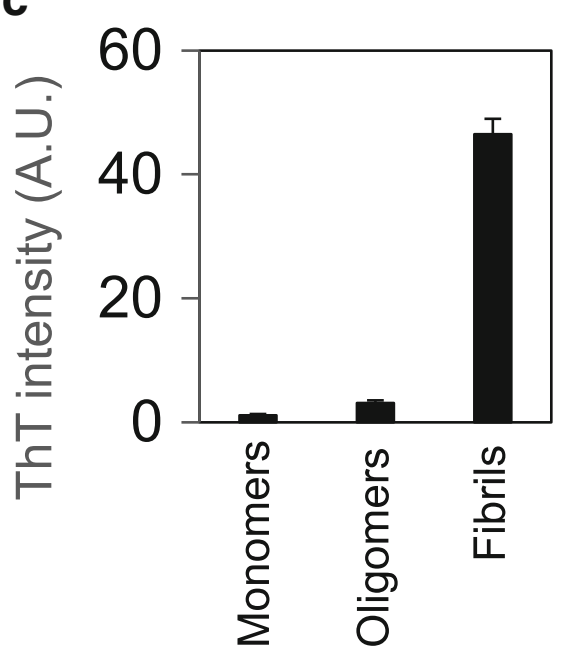

b

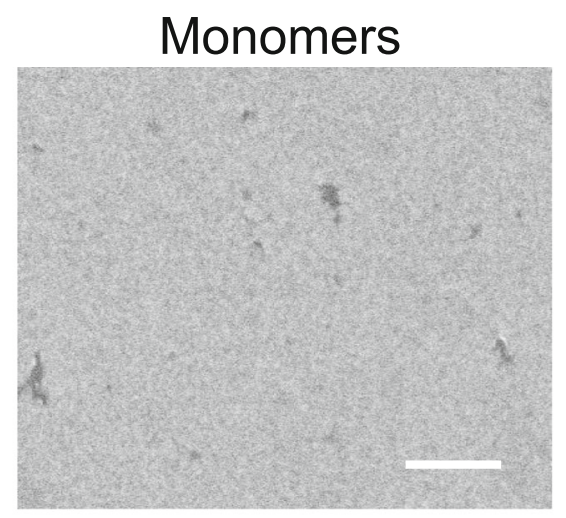

Fibrils

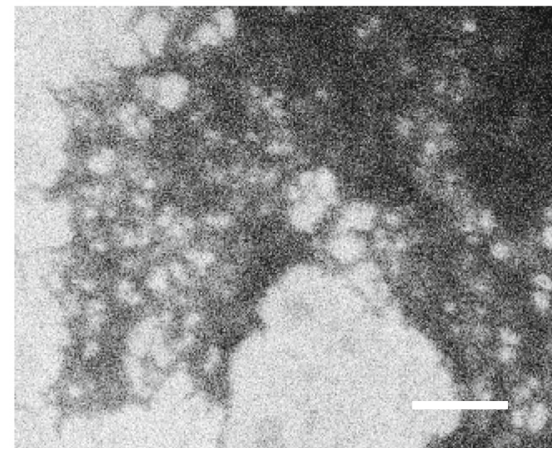

Fig. 1 A 342 oligomerization and morphological changes. a A 342 oligomerization sequences. A 342 monomers (45 $\mu M$ ) were incubated under oligomerization conditions at room temperature for $0 \mathrm{~h}$ (monomers) or for $14 \mathrm{~h}$ (oligomers), or at $37^{\circ} \mathrm{C}$ for $48 \mathrm{~h}$ (fibrils), and applied to $8 \%$ native polyacrylamide gel electrophoresis followed by Western blotting. $\mathbf{b}$ The ThT assay revealed A 342 assembly under oligomerization conditions at room temperature for $0 \mathrm{~h}$ (monomers) or $14 \mathrm{~h}$ (oligomers), or at $37^{\circ} \mathrm{C}$ for $48 \mathrm{~h}$ (fibrils). c Morphological images of A 42 samples under oligomerization conditions for $0 \mathrm{~h}$ at room temperature (monomers) or for $48 \mathrm{~h}$ at $37^{\circ} \mathrm{C}$ (fibrils). Scale bars are $500 \mathrm{~nm}$

SEM and native PAGE analyses also supported that the A $\beta 42$ monomer sample lacked oligomers and fibrils (Fig. 1a, c).

\section{$A \beta$ oligomerization induced interaction between NLRP3 and ASC in the cell-free system}

C-terminal biotinylated full-length NLRP3 (NLRP3FL-Btn), N-terminal FLAG-tagged full-length ASC (FLAG-ASC-FL), and FLAG-tagged CARD-only ASC (FLAG-ASC-CARD) are schematically indicated in Fig. 2a. Using wheat germ cell-free system-specific expression plasmids, NLRP3-FL-Btn, FLAG-ASC-FL, and FLAG-ASC-CARD proteins were also synthesized, as described previously [5].

Next, we investigated whether $\mathrm{A} \beta$ monomers, oligomers, and fibrils interacted with NLRP3 under cell-free conditions with ALPHA. Direct interactions between NLRP3-FL-Btn and $A \beta$ oligomers or $A \beta$ fibrils were observed in a dose-dependent manner (Fig. 2b, oligomers and fibrils, respectively). However, no interaction between NLRP3-FL-Btn and $A \beta$ monomers was observed (Fig. $2 \mathrm{~b}$, monomers). We further confirmed the interaction between NLRP3-FL-Btn and $A \beta$ fibrils. The ALPHA signals of the interaction gradually increased with $5.4 \mu \mathrm{g} / \mathrm{mL}$ of $A \beta$ fibrils and decreased at higher concentrations of $A \beta$ fibrils (Fig. 2c).

Next, we tested whether $A \beta$ induced the interaction between NLRP3-FL-Btn and FLAG-ASC-FL. Both A $\beta$ oligomers and $A \beta$ fibrils significantly induced the interaction between NLRP3-FL-Btn and FLAG-ASC-FL in the cell-free system (Fig. 2d, oligo and fibrils, respectively). Positive controls of poly $(\mathrm{I}: \mathrm{C})$ also induced the interaction between NLRP3-FL-Btn and FLAG-ASC-FL (Fig. 2d, poly(I:C)). 

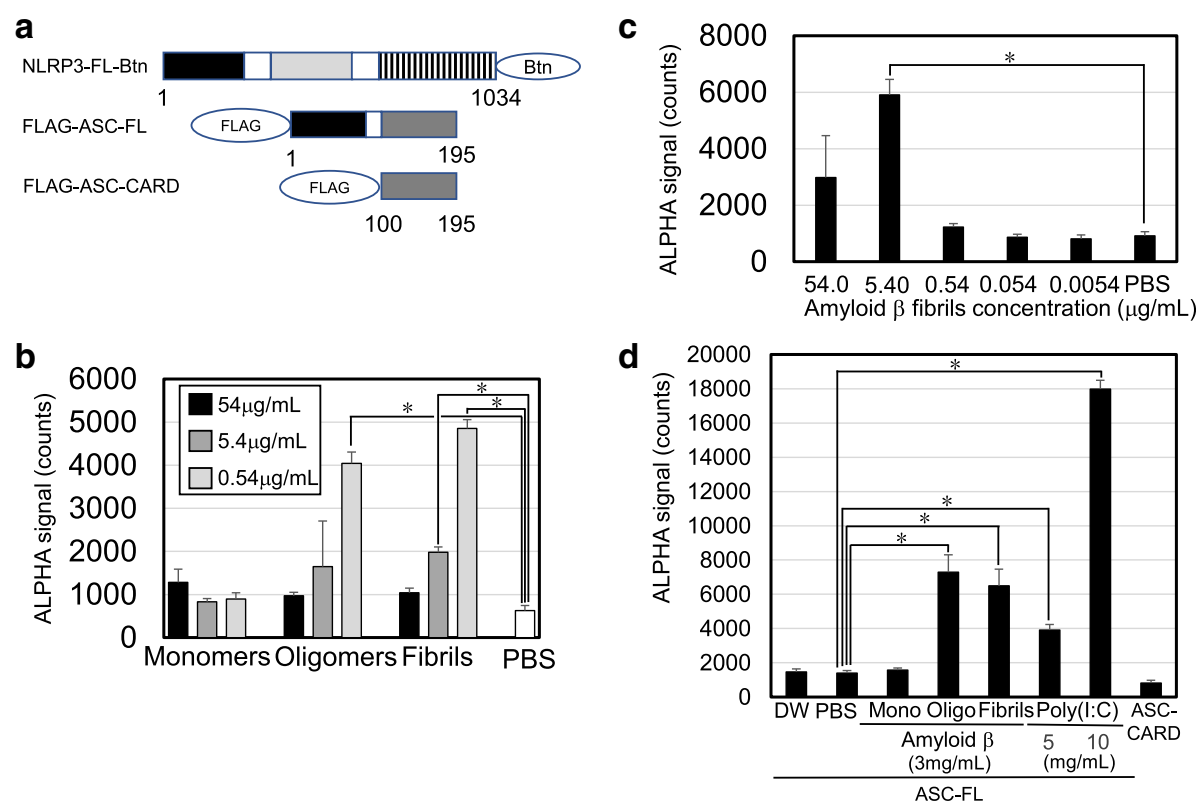

Fig. 2 Direct interaction between $A \beta$ and NLRP3 induced the initial event of NLRP3 inflammasome activation. a Schematic representations of NLRP3 and ASC. Synthetic C-terminal biotinylated full-length NLRP3 (NLRP3-FL-Btn), N-terminal FLAG-tagged ASC (FLAG-ASC-FL), and N-terminal FLAG-tagged ASC-CARD (FLAG-ASC-CARD) are indicated. The pyrin domain (PYD) is indicated by black boxes. The caspase recruitment domain (CARD) is indicated by a dark gray box. The nucleotide-binding oligomerization domain (NOD) is indicated by a light gray box. Leucine-rich repeats are indicated by a striped box. Amino acid sequence numbers are indicated under each schematic. $\mathbf{b}$ Interaction between NLRP3-FL-Btn and each form of $A \beta$ with indicated concentrations is presented. $\mathbf{c}$ Interaction between NLRP3-FL-Btn and A $\beta$ fibrils with indicated concentrations is presented. $\mathbf{d}$ Interaction between NLRP3-FL-Btn and FLAG-ASC-FL upon incubation with each form of A $\beta$ with indicated concentrations. Interactions between NLRP3-FL-Btn and FLAG-ASC-FL upon incubation with poly(l:C) were positive controls. Interaction between NLRP3-FL-Btn and FLAG-ASC-CARD was the negative control. Interaction was detected by an amplified luminescent proximity homogeneous assay (ALPHA). Results are given as means \pm standard deviation of triplicate data acquisition. ${ }^{*} p$ value $<0.05$ was considered significant

$A \beta$ oligomers, but not $A \beta$ fibrils, induced IL-1 $\beta$ secretion from 293T cells with expression plasmids

The cell-based assay using $293 \mathrm{~T}$ cell expression plasmids revealed that $A \beta$ oligomers at 10 and $100 \mathrm{nM}$, but not monomers or fibrils, were able to activate the reconstitutedintracellular NLRP3 inflammasome leading to IL-1 $\beta$ secretion (Fig. 3a). In a cell-based assay using $293 \mathrm{~T}$ cells, A $\beta$ fibrils did not induce IL-1 $\beta$ secretion, different from the cell-free system (Fig. 1).

\section{$A \beta$ oligomers induced IL-1 $\beta$ secretion and caspase-1 activation in human peripheral mononuclear cells}

The physiological relevance was evaluated using human MNCs incubated with $\mathrm{A} \beta$ oligomers. Consistent with the cell-based assay using $293 \mathrm{~T}$ cells, A $\beta$ oligomers at 10 and $100 \mathrm{nM}$ induced even low but significant IL-1 $\beta$ secretion from human MNCs and caspase-1 activation (Fig. 3b, c).

\section{Specificity of the cell-free assay system}

To test the specificity of the cell-free assay system, the interactions between NLRP3-Btn or GFP-Btn and $4.5 \mu \mathrm{M}$ $\mathrm{A} \beta$ were assessed. The ALPHA-positive ratio of the interaction between NLRP3-Btn and A $\beta$ was much higher than that between GFP-Btn and A $\beta$ (Additional file 1: Figure $\mathrm{S} 1)$. Therefore, NLRP3 was able to specifically recognize $\mathrm{A} \beta$ in comparison with GFP (Additional file 1: Figure S1).

\section{Effects of known NLRP3 inhibitors on the interaction} between FLAG-NLRP3-FL and $A \beta$ in the cell-free system We investigated the interaction between NLRP3 and A $\beta$ oligomers and fibrils using MCC950 and isoliquiritigenin, known as NLRP3 inhibitors, in the cell-free system. The positive ALPHA signal rates for the interaction between FLAG-NLRP3-FL and $A \beta$ oligomers or $A \beta$ fibrils in the presence of $50 \mu \mathrm{M}$ MCC950 in distilled water were not reduced compared with distilled water alone $(p=0.275)$ (Additional file 2: Figure S2A). Furthermore, positive ALPHA signal rates for the interaction between FLAG-NLRP3-FL and A $\beta$ oligomers or $A \beta$ fibrils in the presence of $50 \mu \mathrm{M}$ isoliquiritigenin in $1 \%(v / v)$ DMSO were not reduced compared with $1 \%(v / v)$ DMSO alone $(p=0.275)$ (Additional file 2: Figure S2B).

\section{Endotoxin contamination in $A \beta$}

Endotoxin contamination in $A \beta$ monomers, oligomers, and fibrils was in an undetectable level. 

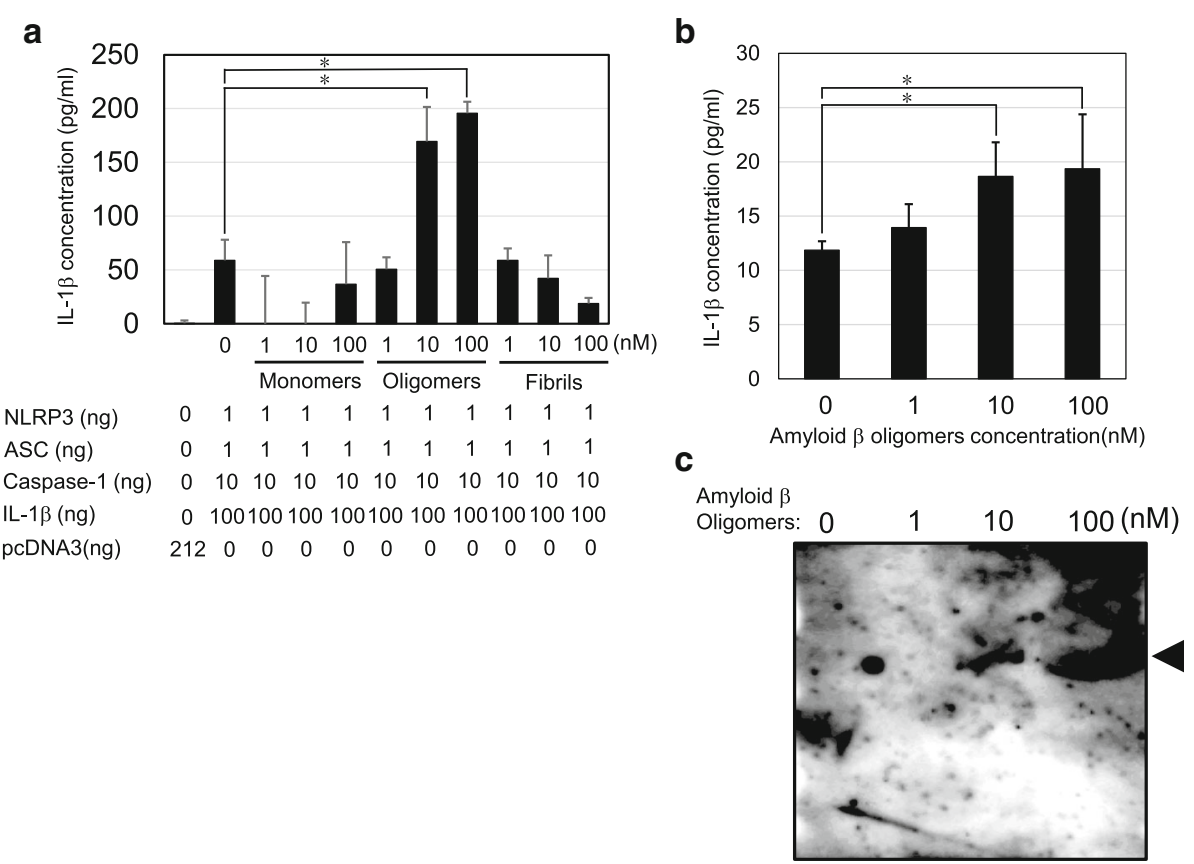

Fig. 3 IL-1 $\beta$ secretion from living cells.a Cell-based assay using human embryonic kidney (HEK) 293T cells transfected with NLRP3, ASC, caspase-1, and IL-1 $\beta$. IL-1 $\beta$ concentrations were evaluated by ELISA after a 16-h incubation with A $\beta$ monomers, oligomers, or fibrils. b Cell-based assay using human peripheral mononuclear cells. IL-1 $\beta$ concentrations were evaluated by ELISA after a 16-h incubation with A $\beta$ oligomers. c Caspase-1 activation in cell lysates was detected by immunoblotting corresponding to $\mathbf{b}$. Cleaved-caspase-1 is indicated by arrowheads

\section{Discussion}

AD has been reported as a neuroinflammatory disease linked to the pathogenesis of the hyper-secretion of IL-1 $\beta$ via the activation of the NLRP3 inflammasome [4]. Lysosomal damage caused by $\mathrm{A} \beta$ oligomers following ROS production has been reported to induce the NLRP3 inflammasome in microglial cells in AD $[9,11]$. This $\mathrm{A} \beta$ oligomerization-initiated ROS-mediated NLRP3 inflammasome activation scenario has been accepted [12], but the possibility that $A \beta$ directly initiates the NLRP3 inflammasome cannot be excluded.

The purpose of our study was to clarify whether $A \beta$ oligomers directly or indirectly activate the NLRP3 inflammasome. Numerous ligands, including $A \beta$, have been reported to activate the NLRP3 inflammasome; however, none were confirmed at the molecular level in previous reports.

In order to identify directly stimulating endogenous ligands, we previously developed a reconstituted NLRP3 inflammasome in a cell-free system $[5,13]$. In this study, we successfully prepared $A \beta$ oligomers and $A \beta$ fibrils (Fig. 1) and found that oligomerized $A \beta$ directly interacted with NLRP3 and induced the interaction of NLRP3 and ASC in the cell-free system, which may be an initial event in NLRP3 inflammasome activation (Fig. 2). Although the cell-free system cannot fully reflect physiological events, this study provides evidence that helps clarify the $\mathrm{AD}$ pathogenesis, being consistent with a report that $A \beta$ causes lysosomal damage, inducing ROS-mediated NLRP3 inflammasome activation [9].

Under cell-free conditions, $A \beta$ oligomers and fibrils, but not monomers, interacted with NLRP3 (Fig. 2). As for inflammasome-related intracellular pattern recognition receptors, NLRP3 and AIM2 were reported to recognize poly(I:C) and poly(dA:dT), both of which are large-molecular-weight nucleic acid polymers, to assemble the NLRP3 and AIM2 inflammasomes [14-17]. NLRC4 was reported to recognize flagellin, which can oligomerize to form fibrils to assemble the NLRC4 inflammasome [18, 19]. Pyrin was reported to recognize actin, which can oligomerize to form fibrils to assemble the pyrin inflammasome $[20,21]$. In this context, fibril formation is considered to play an important role in inflammasome formation. Indeed, fibril formation was reported to be based on conformational changes in vitro [22]. According to a study of $A \beta, A \beta$ monomers show lower radius of gyration than the $A \beta$ oligomers, which may be related to the binding capacity of NLRP3, resulting in NLRP3 inflammasome activation [23]. This hypothesis may explain why the $A \beta$ monomers did not interact with NLRP3.

Unlike LPS, which is a well-known strong IL-1 $\beta$ inducer, $A \beta$ oligomers induced even low-level IL- $1 \beta$ secretion from NLRP3 inflammasome-reconstituted-293T cells and human MNCs (Fig. 3a, b). On the other hand, $A \beta$ fibrils were unable to induce such IL-1 $\beta$ secretion in the cell-based 
assay, being different from the cell-free assay (Fig. 3). We speculate that because $A \beta$ forms a large complex from oligomers to fibrils, it can only reach intracellular NLRP3 in very low amounts. This may explain why little activated caspase- 1 from PMCs was detected on immunoblotting (Fig. 3c).

We next examined the specificity of the cell-free system for NLRP3 versus green fluorescence protein (GFP) and found that NLRP3 was able to more specifically recognize $\mathrm{A} \beta$ as compared with GFP (Additional file 1: Figure S1); however, this does not rule out redundant functions of inflammasomes.

We also investigated the effects of the known NLRP3 inhibitors MCC950 and isoliquiritigenin $[24,25]$ on the interaction between FLAG-NLRP3-FL and $A \beta$ in the cell-free system; however, there was no significant inhibition (Additional file 2: Figures S2A and S2B). These data suggest that there may be targets of inhibitors other than the $A \beta$ recognition site.

\section{Conclusions}

A $\beta$ oligomers directly interact with NLRP3 to activate the NLRP3 inflammasome. This interaction may provide an attractive drug target to avoid neuroinflammation in AD therapy, although there are mechanisms for the NLRP3 inflammasome and AD pathology of the human brain that still require elucidation [26]. Our data may provide further understanding of these mechanisms.

\section{Additional files}

Additional file 1: Figure S1. Specificity of ALPHA-positive ratio for the interaction between A $\beta$ and NLRP3 in comparison with GFP. (PPTX $42 \mathrm{~kb}$ )

Additional file 2: Figure S2. MCC950 (A) and isoliquiritigenin (B), known NLRP3 inhibitors, did not affect the interaction between FLAGNLRP3-FL and A oligomers or fibrils in the cell-free system. (PPTX $51 \mathrm{~kb}$ )

\section{Abbreviations}

AD: Alzheimer's disease; ALPHA: Amplified luminescent proximity homogeneous assay; ASC: Apoptosis-associated speck-like protein containing a caspase recruitment domain; CARD: Caspase recruitment domain; IL: Interleukin; NLRP: NACHT, LRR, and PYD domain-containing protein; ROS: Reactive oxygen species

\section{Acknowledgements}

We thank the Advanced Research Support Center, Ehime University, for the technical assistance.

\section{Funding}

This work was supported by the Platform for Drug Discovery, Informatics and Structural Life Science from the Ministry of Education, Culture, Sports, Science and Technology, Japan (H.T., T.S., and J.M.); the Center for Clinical and Translational Research of Kyushu University (J.M.); and Grants-in-Aid for Scientific Research (JSPS KAKENHI grant numbers $17 \mathrm{H} 04656$ and 17K19685) from The Ministry of Education, Culture, Sports, Science and Technology, Japan (J.M.) and 15K08597 (T.Z.).

Availability of data and materials Not applicable.

\section{Authors' contributions}

AN, NK, and JM conceived and devised the study. HT, TS, SM, MK, TY, TZ, and $J M$ were responsible for the acquisition of data. AN, NK, TZ, ASM, and JM analyzed the data. All authors contributed to the interpretation of the data. AN, NK, TZ, and JM drafted the manuscript. All authors critically reviewed and edited the manuscript. JM is the guarantor of this work. The manuscript was written by AN, NK, and JM, and all authors read and approved the final manuscript.

Ethics approval and consent to participate

Not applicable.

\section{Consent for publication}

Not applicable.

\section{Competing interests}

All authors declare that they have no competing interests.

\section{Publisher's Note}

Springer Nature remains neutral with regard to jurisdictional claims in published maps and institutional affiliations.

\section{Author details}

${ }^{1}$ Department of Pathology, Ehime University Graduate School of Medicine and Proteo-Science Centre, Shitsukawa 454, Toon, Ehime 791-0295, Japan. ${ }^{2}$ Department of Chemistry and Biology, Ehime University Graduate School of Science and Engineering, Bunkyocho 2-5, Matsuyama, Ehime 790-8577, Japan. ${ }^{3}$ Divison of Proteo-Drug-Discovery Sciences, Ehime University Proteo-Science Center, Bunkyocho 3, Matsuyama, Ehime 790-8577, Japan. ${ }^{4}$ Division of Cell-free Sciences, Ehime University Proteo-Science Center, Bunkyocho 3, Matsuyama, Ehime 790-8577, Japan.

Received: 15 February 2018 Accepted: 3 September 2018

Published online: 12 November 2018

\section{References}

1. Huang Y, Mucke L. Alzheimer mechanisms and therapeutic strategies. Cell. 2012;148:1204-22

2. Martinon F, Mayor A, Tschopp J. The inflammasomes: guardians of the body. Annu Rev Immunol. 2009;27:229-65.

3. Alnemri ES. Sensing cytoplasmic danger signals by the inflammasome. J Clin Immunol. 2010;30:512-9.

4. Franchi L, Eigenbrod T, Muñoz-Planillo R, Nuñez G. The inflammasome: a caspase-1-activation platform that regulates immune responses and disease pathogenesis. Nat Immunol. 2009;10:241-7.

5. Kaneko N, Ito Y, Iwasaki T, Takeda H, Sawasaki T, Migita K, Agematsu K, Koga T, Kawakami A, Yachie A, Yoshiura K, Morikawa S, Kurata M, Masumoto J. Poly (l:C) and hyaluronic acid directly interact with NLRP3, resulting in the assembly of NLRP3 and ASC in a cell-free system. Eur J Inflamm. 2017;15:85-97.

6. Halle A, Hornung V, Petzold GC, Stewart CR, Monks BG, Reinheckel T, Fitzgerald KA, Latz E, Moore KJ, Golenbock DT. The NALP3 inflammasome is involved in the innate immune response to amyloid- $\beta$. Nat Immunol. 2008; 9:857-65.

7. Salminen A, Ojala J, Suuronen T, Kaarniranta K, Kauppinen A. Amyloid- $\beta$ oligomers set fire to inflammasomes and induce Alzheimer's pathology. J Cell Mol Med. 2008;12:2255-62.

8. Vanltallie TB. Alzheimer's disease: innate immunity gone awry? Metabolism. 2017;69S:S41-9.

9. Parajuli $B$, Sonobe $Y$, Horiuchi $H$, Takeuchi $H$, Mizuno $T$, Suzumura A. Oligomeric amyloid $\beta$ induces $\mathrm{IL}-1 \beta$ processing via production of ROS: implication in Alzheimer's disease. Cell Death Dis. 2013;4:e975.

10. Naiki H, Higuchi K, Hosokawa M, Takeda T. Fluorometric determination of amyloid fibrils in vitro using the fluorescent dye, thioflavin T1. Anal Biochem. 1989;177:244-9.

11. Labzin LI, Heneka MT, Latz E. Innate immunity and neurodegeneration. Annu Rev Med. 2018;69:437-49.

12. Heneka MT. Inflammasome activation and innate immunity in Alzheimer's disease. Brain Pathol. 2017;27:220-2.

13. Kaneko N, Iwasaki T, Ito Y, Takeda H, Sawasaki T, Morikawa S, Nakano N, Kurata M, Masumoto J. Applications of reconstituted inflammasomes in a 
cell-free system to drug discovery and elucidation of the pathogenesis of autoinflammatory diseases. Inflamm Regen. 2017;37:9.

14. Fernandes-Alnemri T, Yu JW, Datta P, Wu J, Alnemri ES. AlM2 activates the inflammasome and cell death in response to cytoplasmic DNA. Nature. 2009;458:509-13.

15. Hornung V, Ablasser A, Charrel-Dennis M, Bauernfeind F, Horvath G, Caffrey DR, Latz E, Fitzgerald KA. AIM2 recognizes cytosolic dsDNA and forms a caspase-1-activating inflammasome with ASC. Nature. 2009;458:514-8.

16. Allen IC, Scull MA, Moore CB, Holl EK, McElvania-TeKippe E, Taxman DJ, Guthrie EH, Pickles RJ, Ting JP. The NLRP3 inflammasome mediates in vivo innate immunity to influenza $A$ virus through recognition of viral RNA. Immunity. 2009;30:556-65.

17. Rajan JV, Warren SE, Miao EA, Aderem A. Activation of the NLRP3 inflammasome by intracellular poly I:C. FEBS Lett. 2010;584:4627-32.

18. Miao EA, Alpuche-Aranda CM, Dors M, Clark AE, Bader MW, Miller SI, Aderem A. Cytoplasmic flagellin activates caspase-1 and secretion of interleukin 1B via Ipaf. Nat Immunol. 2006;7:569-75.

19. Franchi L, Amer A, Body-Malapel M, Kanneganti TD, Ozören N, Jagirdar R, Inohara N, Vandenabeele P, Bertin J, Coyle A, Grant EP, Núñez G. Cytosolic flagellin requires Ipaf for activation of caspase- 1 and interleukin $1 \beta$ in salmonella-infected macrophages. Nat Immunol. 2006;7:576-82.

20. Mansfield E, Chae JJ, Komarow HD, Brotz TM, Frucht DM, Aksentijevich I, Kastner DL. The familial Mediterranean fever protein, pyrin, associates with microtubules and colocalizes with actin filaments. Blood. 2001;98:851-9.

21. Kim ML, Chae JJ, Park YH, De Nardo D, Stirzaker RA, Ko HJ, Tye H, Cengia L, DiRago L, Metcalf D, Roberts AW, Kastner DL, Lew AM, Lyras D, Kile BT, Croker BA, Masters SL. Aberrant actin depolymerization triggers the pyrin inflammasome and autoinflammatory disease that is dependent on IL-18, not IL-1ß. J Exp Med. 2015;212:927-38.

22. Naiki $H$, Higuchi $K$, Nakakuki $K$, Takeda T. Kinetic analysis of amyloid fibril polymerization in vitro. Lab Investig. 1991;65:104-10.

23. Nag S, Sarkar B, Bandyopadhyay A, Sahoo B, Sreenivasan VK, Kombrabail M, Muralidharan C, Maiti S. Nature of the amyloid- $\beta$ monomer and the monomer-oligomer equilibrium. J Biol Chem. 2011;286:13827-33.

24. Coll RC, Robertson A, Butler M, Cooper M, O'Neill LA. The cytokine release inhibitory drug CRID3 targets ASC oligomerisation in the NLRP3 and AIM2 inflammasomes. PLoS One. 2011:6:e29539.

25. Honda H, Nagai Y, Matsunaga T, Okamoto N, Watanabe $Y$, Tsuneyama $K$, Hayashi H, Fujii I, Ikutani M, Hirai Y, Muraquchi A, Takatsu K. Isoliquiritigenin is a potent inhibitor of NLRP3 inflammasome activation and diet-induced adipose tissue inflammation. J Leukoc Biol. 2014;96:1087-100.

26. Salminen A, Ojala J, Kauppinen A, Kaarniranta K, Suuronen T. Inflammation in Alzheimer's disease: amyloid- $\beta$ oligomers trigger innate immunity defence via pattern recognition receptors. Prog Neurobiol. 2009;87:181-94.

Ready to submit your research? Choose BMC and benefit from:

- fast, convenient online submission

- thorough peer review by experienced researchers in your field

- rapid publication on acceptance

- support for research data, including large and complex data types

- gold Open Access which fosters wider collaboration and increased citations

- maximum visibility for your research: over $100 \mathrm{M}$ website views per year

At BMC, research is always in progress.

Learn more biomedcentral.com/submissions 